\title{
About dependence of parameters of internal explosion on the device of safety designs in apertures of the protecting walls of the production and residential buildings
}

\author{
Vyacheslav Gorev* \\ Moscow State University of Civil Engineering, Yaroslavskoe shosse, 26, Moscow, 129337, Russia
}

\begin{abstract}
Protection of buildings against consequences of gas explosion indoors by means of the safety designs (SD) is widespread. In a number of the regulating documents requirements to these designs are imposed. It agrees, the regulating documents are allowed to carry out calculation of system of protection against internal explosion by means of the safety designs. The key sizes determining the area of apertures of the blocked safety designs are: speed of explosive combustion, most allowed explosion pressure, unit weight (per acre) the safety designs and pressure of opening of the safety designs. Under pressure openings it is meant pressure with which communications of the safety designs with walls of the building collapse and the safety designs starts moving. Depth of seal of the safety designs in an aperture remains out of sight and is supposed what influences the end result a little. In the real article an attempt to deal with this question is made. As a result of the conducted researches it was established that depth of seal of the safety designs in an aperture has to be considered when calculating system of protection of buildings against internal explosion by means of the safety designs. Especially it is important for rooms of small volume of $\mathrm{V}_{0} \leq 120 \mathrm{of} \mathrm{m}^{3}$. For the analysis of explosion in the production buildings it is necessary to consider the volume of these rooms and a possibility of increase in burning rate because of existence of barriers indoors.
\end{abstract}

\section{Introduction}

Explosions of household gas in residential buildings became the real national problem. Frequent reports from the place of events, messages about a death toll and the reasons of the incident are alarming and will mobilize to carrying out the analysis of the reasons and consequences of explosions of gas in premises. The safety designs (SD) are without fail applied to protection against action of an overpressure at internal emergency explosion on the industrial facilities if these objects are referred to category explosive [1]. At the same time the area of apertures which have to be blocked [2,3] is regulated. Also requirements to

* Corresponding author: Kafedrapd@yandex.ru 
the safety designs, namely, to their area, in case of the collapsing glasses, and to weight on $1 \mathrm{~m}^{2}$, in case of the safety designs located in a covering are regulated.

Destruction of glasses depends on a form, and thickness of sheets of glazing [3] and also on quantity of glazing [4]. For the safety designs located in a covering it is required that their average weight on $1 \mathrm{~m}^{2}$ did not exceed $70 \mathrm{~kg} / \mathrm{m}^{2}$.

Residential buildings and kitchen rooms are not characterized as explosive, and special events to their protection against explosion are not provided. Frequent explosions of household gas in houses force to pay an attention to this problem, in particular, to raise a question of use of the safety designs in kitchen rooms. For more fruitful consideration of a question it is necessary to remember the highlights taking place at internal explosion. Further the quasistatic nature of explosion is supposed [5-6].

\section{Methods and technique}

Explosive combustion is deflagration and begins in pressure-tight volume. Change of pressure at the same time is described by expression [7-8]:

$$
\frac{P_{(t)}-P_{0}}{P_{M}-P_{0}}=\frac{m_{(t)}}{m_{0}}
$$

Here $\mathrm{P}_{(\mathrm{t})}$ - the current pressure indoors, $\mathrm{P}_{\mathrm{M}}$ - the maximal pressure of explosion in completely pressure-tight volume.

$\mathrm{P}_{\mathrm{M}}$ - depends on properties of original gas mixture in completely gas-polluted volume. If to accept that design admissible pressure $\Delta \mathrm{P}_{\mathrm{d}}$ is, approximately, $\Delta \mathrm{P}_{\mathrm{d}}=7 \mathrm{kPa}$, of $\mathrm{P}_{\mathrm{M}}=800$ $\mathrm{kPa}$, then from (1) assessment follows:

$$
\frac{\Delta P d}{\Delta P_{M}}=\frac{m_{(t)}}{m_{0}}=10^{-2}
$$

This assessment shows that even at gas contamination of $1 \%$ pressure of explosion will already reach the design allowed value. Estimated values of admissible pressure are defined by calculation on a carrying capacity for the first group of the limiting conditions [4,9-12].

Follows from expression (1):

$$
\frac{\Delta P_{(t)}}{P_{0}}=\Delta P_{M} \frac{4 \pi \frac{(\sigma-1) \sigma^{3}}{\sigma} U_{g 1}{ }^{3} t^{3}}{3 V_{0}}=\gamma \frac{\sigma-1}{\sigma} \frac{V_{(t)}}{V_{0}}
$$

In expression (2) $\gamma=\frac{C_{p}}{C_{V}}$ for products of combustion. At $\gamma=1,27$ and $\overline{P_{M}}=\frac{P_{M}}{P_{0}}=8$, $\sigma=6,5$.

From (2) it is visible that pressure on an incipient state of explosion grows in proportion up $U_{21}^{3} \sigma^{3} t^{3}$ to the pressure $\Delta \mathrm{P}_{0 \mathrm{~T}}$ and until $\mathrm{t}=\mathrm{t}_{0 \mathrm{t}}$ (Fig. 1).

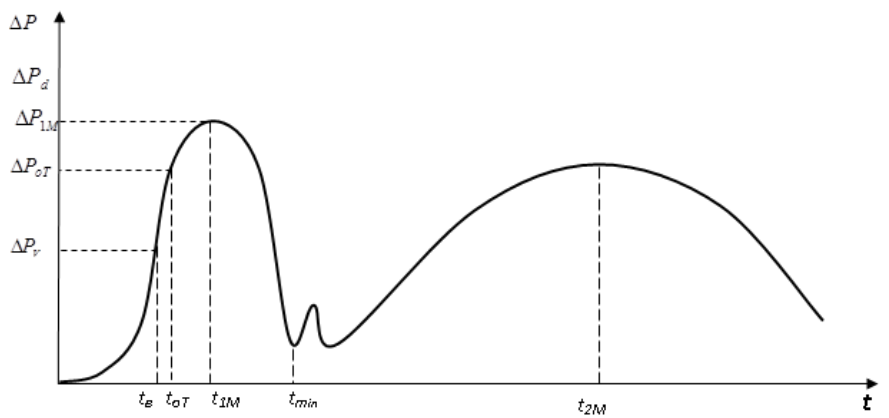

Fig. 1. The nature of change of pressure at explosion in volume with the opened apertures. 
In fig. $1-\Delta \mathrm{P}_{\mathrm{v}}-$ pressure of opening of the safety designs, corresponds to an instant of destruction of fastening of the safety designs to a building framework, $\Delta \mathrm{P}_{0 \mathrm{~T}}-$ pressure with which apertures open for the expiration of gases in $t_{0 T}$ instant. From $t_{v}$ moment until $t_{0 T}$ safety designs moves in an aperture, without opening space for the expiration of gases, Fig. 2.

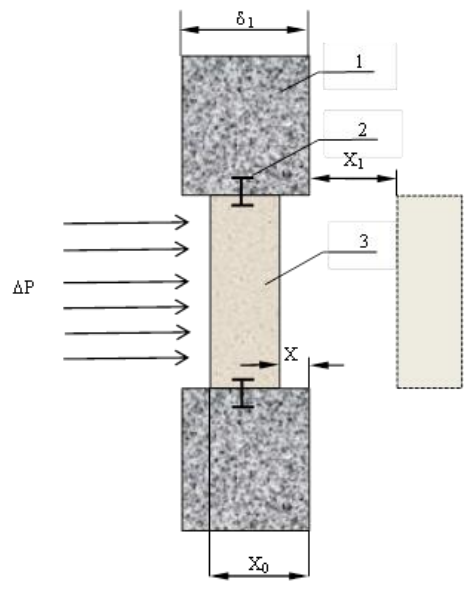

Fig. 2. The movement safety designs in an aperture.

It means that volume during time $0-\mathrm{t}_{0 \mathrm{~T}}$ remains pressure-tight though in an interval of time from $t_{V}$ to $t_{0 T}$ safety designs are in driving. We neglect increase in volume during driving. After the beginning of opening of space for the expiration of gases pressure grows in volume up to the size $\Delta \mathrm{P}_{1 \mathrm{M}}$ during time $\Delta t_{1}=t_{1 M}-t_{0 T}$.

At the same time the area $(S)$ of open space for the expiration of gases at the time of $t_{1 M}$ is equal:

$$
S_{1 M}=X_{1 M} \Pi
$$

\section{Results}

So, after destruction of fastenings of the safety designs to walls they begin to move in an aperture. The equation of motion of the safety designs has an appearance:

$$
M \frac{d^{2} X}{d t^{2}}=a b^{*} \Delta P(t)
$$

$\mathrm{X}=0, \mathrm{dX} / \mathrm{dt}=0$ at $\mathrm{t}=0 ; \Delta \mathrm{P}(0)=\Delta \mathrm{P}_{0 \mathrm{~T}}, \mathrm{M}-$ the mass of a safety design, $\mathrm{a} * \mathrm{~b}-$ the area of the personal computer, $\Delta \mathrm{P}(\mathrm{t})$ - pressure operating on the safety designs from the moment of $t_{v}$ until $t_{0 T}$ when the safety designs passes a path of $X_{0}$ and begins to open space for the gas expiration. The solution of the equation (3) on site $0-X_{0}$ or from $t_{v}$ to $t_{0 T}$, has an appearance:

$$
\begin{gathered}
\bar{X}=\frac{B}{4}\left[\frac{(1+\theta)^{5}}{5}-\theta-\frac{1}{5}\right] \\
B=\frac{a b t_{v}{ }^{2} \Delta P_{v}}{M X_{0}}: t_{B}=\frac{1}{U_{g 1} \sigma}\left[\frac{3 \Delta P_{V} V_{0} \sigma}{P_{0} 4 \pi \gamma(\sigma-1)}\right]^{1 / 3} ; \bar{X}=\frac{X}{X_{0}} ; \theta=\frac{t-t_{v}}{t_{v}} .
\end{gathered}
$$


After achievement of value $\bar{X}=1$ the space for the expiration of gases begins to open. The first passage time of the moment of opening $\theta_{0}=\frac{t_{o T}-t_{V}}{t_{V}}$ is defined from a condition from $\bar{X}=1(4)$ :

$$
\frac{4}{B}=\left[\frac{\left(1+\theta_{0}\right)^{5}}{5}-\left(1+\theta_{0}\right)+\frac{4}{5}\right]
$$

Traveling speed of the safety designs at the time of the beginning of opening of an aperture at, $\bar{X}=1, \mathrm{t}=\mathrm{t}_{\mathrm{v}}, \theta=\theta_{0}$ is defined by expression:

$$
\left.\frac{d \bar{X}}{d \theta}\right|_{\substack{\bar{X}=1 \\ \theta=\theta_{0}}}=\frac{B}{4}\left[\left(1+\theta_{0}\right)^{4}-1\right]
$$

Results of calculation of time of opening of $t_{v}$, and time of the beginning of opening of $\mathrm{t}_{0 \mathrm{~T}}$ depending on the volume of the room and the size $\Delta \mathrm{P}_{\mathrm{V}}$ or $\Delta \mathrm{P}_{0 \mathrm{~T}}$ are presented in table 1. Calculations are given for the size of $U_{21}=3,1 * U_{H}=3,1 * 0,35=1,085 \mathrm{~m} / \mathrm{s}$ and $\sigma=6,5$, $\gamma=1,27$.

Table 1. Results of calculation of time of opening of $\mathrm{tB}$, and time of the beginning of opening of tot depending on the volume of the room and the size $\Delta \mathrm{P}_{\mathrm{V}}$.

\begin{tabular}{|c|c|c|c|c|c|c|c|}
\hline $\begin{array}{c}\mathrm{V}, \mathrm{M}^{3} \\
\Delta P_{V}, \mathrm{kPa}\end{array}$ & 30 & 40 & 50 & 60 & 100 & 120 & 150 \\
\hline 2 & 0.0725 & 0.08 & 0.086 & 0.091 & 0.108 & 0.115 & 0.124 \\
\hline 5 & 0.0984 & 0.109 & 0.117 & 0.123 & 0.147 & 0.156 & 0.167 \\
\hline 7 & 0.11 & 0.121 & 0.13 & 0.138 & 0.164 & 0.174 & 0.188 \\
\hline 10 & 0.124 & 0.137 & 0.147 & 0.156 & 0.185 & 0.197 & 0.21 \\
\hline 15 & 0.142 & 0.156 & 0.168 & 0.178 & 0.21 & 0.2255 & 0.243 \\
\hline
\end{tabular}

In table 1 time in seconds by the time of achievement of the corresponding pressure of explosion in the pressure-tight volume of $\mathrm{V}_{0}$ is given, to $\mathrm{m}^{3}$. The difference of valium in lower line and in the line located above in the same column gives time of the movement safety designs in an aperture from the moment of destruction of fastenings of the safety designs $-t_{v}$, until opening of an aperture of tot. Follows from the analysis of table 1 that at a slight difference of times of opening $-\mathrm{t}_{\mathrm{V}}$ and $\mathrm{t}_{0 \mathrm{~T}}$, pressure in volume changes many times and can exceed the allowed pressure before opening of an aperture. Thus, the strict conditions are imposed to the safety designs, that is they have to pass a way in an aperture before its opening in time $\theta_{o}=\frac{\Delta t_{o T}-\Delta t_{V}}{\Delta t_{V}}\ulcorner .1$.

After the beginning of opening of an aperture for the expiration of gases we will present an equation of motion of the safety designs in the form:

$$
M \frac{d^{2} X_{1}}{d t_{1}^{2}}=a b \frac{\Delta P_{o T}+\Delta P_{1 M}}{2}
$$

The datum of movement and timing begins with 0 , and initial value of speed $\left.\frac{d X_{1}}{d t_{1}}\right|_{t_{1}=0}=\left.\frac{d X}{d t}\right|_{t=t_{T T}}$ 
That is at the time of opening of an aperture of the safety designs has already sufficient speed, and further opening of an aperture is defined by the valium of this speed. In $X_{1}\left(t_{1}\right)$ and $t_{1}$ respectively the shift of the safety designs and time of the movement safety designs later began opening of an aperture of $\mathrm{t}_{0 \mathrm{~T}}$.

In the equation (7) $\Delta \mathrm{P}_{1 \mathrm{M}}$ - the maximal pressure in volume after opening of an aperture, it should not be more admissible $\Delta \mathrm{P}_{\mathrm{d}} \geq \Delta \mathrm{P}_{1 \mathrm{M}}$.

The decision (7) has an appearance:

$$
\begin{aligned}
& X_{1}=\frac{a b}{m} \frac{\left(\Delta P_{0 T}+\Delta P_{1 M}\right)}{4} t_{1}^{2}+B_{1} t_{1} \\
& B_{1}=\frac{B X_{0}}{4 t_{V}}\left[\left(1+\theta_{0}\right)^{4}-1\right] \text { или } \bar{B}_{1}=\frac{B}{4}\left[\left(1+\theta_{0}\right)^{4}-1\right]
\end{aligned}
$$

Size $\bar{B}_{1}$ is a dimensionless speed of safety designs at the time of a departure from an aperture.

Time of opening of an aperture is defined from (5) for different B. Size B changes over a wide range and defines time from the beginning of opening before opening. The it is less the larger time moves a safety design before opening of an aperture and higher than pressure in volume at the time of opening.

In the analysis of decisions (8) and (9) $\Delta \mathrm{P}_{0 \mathrm{~T}} \approx \Delta \mathrm{P}_{1 \mathrm{M}}$ is accepted that is fair for mild safety designs. At the same time it turns out:

$$
\bar{X}_{1}=B \theta_{1}\left[\frac{\left(1+\theta_{0}\right)}{2} \theta_{1}+\left(1+\theta_{0}\right)^{4}-1\right]
$$

The dependence of time $t_{01}=t_{V}\left(1+\theta_{0}\right)$, the relation $\frac{\Delta P_{0 T}}{\Delta P_{V}}=\left(1+\theta_{0}\right)^{3}$ and sizes $\bar{B}_{1}$ on parameter B is presented in table 2 .

Table 2. The dependence of time $t_{01}=t_{V}\left(1+\theta_{0}\right)$, the relation $\frac{\Delta P_{0 T}}{\Delta P_{V}}=\left(1+\theta_{0}\right)^{3}$ and sizes $\bar{B}_{1}$ on parameter B.

\begin{tabular}{|c|c|c|c|c|c|}
\hline $\mathrm{B}$ & 1.0 & 2.0 & 4.0 & 8.0 & 16 \\
\hline$t_{o T} / t_{B}=\left(1+\theta_{0}\right)$ & 1.91 & 1.71 & 1.54 & 1.41 & 1.31 \\
\hline$\Delta P_{o T} / \Delta P_{B}=\left(1+\theta_{0}\right)^{3}$ & 7 & 5 & 3.65 & 2.8 & 2.25 \\
\hline $\bar{B}_{1}$ & 3.1 & 3.75 & 4.65 & 5.86 & 8.25 \\
\hline$\Delta \mathrm{P}_{\mathrm{m}}$ & 0.027 & 0.035 & 0.065 & 0.08 & 0.085 \\
\hline$\Delta \bar{X}_{1 M}$ & 0.45 & 0.424 & 0.48 & 0.39 & 0.36 \\
\hline$\theta_{1 M}$ & 0.033 & 0.04 & 0.075 & 0.08 & 0.086 \\
\hline$\rho_{\mathrm{M}}$ & 37.2 & 29.5 & 30 & 25 & 18.5 \\
\hline$X_{0 M}$ & 0.4 & 0.25 & 0.125 & 0.074 & 0.05 \\
\hline
\end{tabular}

The sizes presented in the table №. 2 are received for $\mathrm{V}_{0}=50 \mathrm{~m}^{3}$ conditions $\mathrm{S}_{0}=2.1 \mathrm{~m}^{2}$, $\Delta \mathrm{P}_{\mathrm{V}}=2 \mathrm{kPa}, \Pi=5.9 \mathrm{~m}, \mathrm{U}_{\mathrm{g}}=1.035 \mathrm{~m} / \mathrm{c}, \sigma=6.5$. 
At assessment of the valium $\mathrm{S}_{0} \Delta \mathrm{P}_{\mathrm{d}}=9 \mathrm{kPa}$ and burning rate on the second maximum of $\Delta \mathrm{P}_{\mathrm{M} 1}$ taking into account was accepted [15-18]. Burning rate of $\mathrm{U}_{\mathrm{g} 1}$ was defined on the basis of $[19,20]$.

At the opening aperture from volume gases begin to expire, and pressure in volume is described by expression:

$$
\begin{gathered}
\frac{d \Delta \bar{P}_{1}^{\prime}\left(\theta_{1}\right)}{d \theta_{1}}=A-F \theta_{1} \\
A=\frac{3}{1+\theta_{0}} ; F=0.266 v_{1} \frac{\Pi \Delta P_{V}^{3 / 2}}{\sigma^{2}(\sigma-1) U_{g}^{3}} \frac{\left[\left(1+\theta_{0}\right)^{4}-1\right]}{\rho_{0}^{1 / 2} \rho_{n}\left(1+\theta_{0}\right)^{3 / 2}}
\end{gathered}
$$

Factor $0,266=\frac{3 * 2^{1 / 2}}{4 \pi * \gamma}, \rho_{\Pi}=\frac{M}{a b} \mathrm{~kg} / \mathrm{m}^{3}, v_{1}=0,8, \rho_{0}-$ density of reactant.

$\Pi$ - the perimeter of an aperture is defined after establishment of the required area of open apertures [4, 13-14].

The solution of the equation (11) has an appearance:

$$
\Delta \bar{P}_{1}^{\prime}=A \theta_{1}-\frac{F \theta_{1}^{2}}{2}
$$

From this decision it is visible that pressure after the beginning of opening of an aperture grows, at $\theta_{1 M}=\frac{A}{F}$ the maximum is implemented.

$$
\Delta P_{1 M}=\Delta P_{V}\left(1+\theta_{0}\right)^{3}\left(1+\frac{A}{2 F}\right)
$$

By the time of achievement of the maximal pressure of $\Delta \mathrm{P}_{1 \mathrm{M}}$ the aperture is open not completely. It means that the distance passed by the safety designs after opening of an aperture in time $\Delta t_{M}=\theta_{1 M} t_{V}$ is less than distance of $\mathrm{X}_{2}$ corresponding to a full opening aperture: $X_{2}=\frac{S_{0}}{\Pi}$.

\section{Discussion}

The analysis of the data presented in table 2 shows that at values of the parameters $B=1$ and $\mathrm{B}=2$ explosion pressure before opening of an aperture increased to value of $14 \mathrm{kPa}$ and 10 $\mathrm{kPa}$ respectively, and exceeds admissible value. It means that an object does not conform to requirements for a carrying capacity. It is possible to reduce explosion pressure increase in parameter "B", reducing of the result $\left(\rho_{\Pi} * \mathrm{X}_{0}\right)$. It is useful to consider the possibility to reduce explosion pressure by the time of opening of an aperture $\Delta \mathrm{P}_{0 \mathrm{~T}}$. reducing opening pressure $\Delta \mathrm{P}_{\mathrm{v}}$,

Decrease opening pressure $\Delta \mathrm{P}_{\mathrm{v}}$ from $2 \mathrm{kPa}$ of from of $1 \mathrm{kPa}$ reduces parameter "B" 1,67 times.

For $\mathrm{B}=2$ case the value of this parameter reaches $\mathrm{B}=0,63$ value.

Despite decrease of parameter " $\mathrm{B}$ " due to decrease of pressure of opening, terminal pressure of explosion in pressure-tight volume $\Delta \mathrm{P}_{\text {от }}$ decreases due to decrease $\Delta \mathrm{P}_{\mathrm{v}}$. At $\mathrm{B}=0,63\left(1+\theta_{0}\right)=2,07$ so $\Delta \mathrm{P}_{\text {от }}=8,87 \mathrm{kPa}$ that it is less, than $\Delta \mathrm{P}_{\text {от }}=10 \mathrm{kPa}$ at $\mathrm{B}=2$ and $\Delta \mathrm{P}_{\mathrm{v}}$ $=2 \mathrm{kPa}$ follows from expression (5).

Pressure boost later began the expirations of gases from volume slight and makes usually no more than $10 \%$. Such situation is a direct consequence of dispersal of the safety designs the initial site of driving on the way of $\mathrm{X}_{0}$. 
Increase in parameter "B" leads to decrease of terminal pressure of explosion only in case of decrease of the result $\left(\rho_{\Pi} * X_{0}\right)$. Decrease of size $\rho_{\Pi}$ is limited. Size $\rho_{\Pi}=10 \mathrm{~kg} / \mathrm{m}^{3}$ at $\mathrm{B}=30$ value is already close to the limiting. Decrease of the size $\mathrm{X}_{0}$ to 0 , is possible and is reached by fastening of the safety designs to an external wall of a protection or profiling, the corresponding expansion of an aperture.

As as it was shown, seal of the safety designs in an aperture leads to noticeable, and sometimes and to the significant increase in pressure of explosion during process of an unclosing of an aperture, there is a need to analyse influence of various parameters on pressure boost. The greatest growth rate of pressure at internal explosion is observed before opening of apertures. The maximal rise in pressure in this case is controlled by parameter "B". The parameter "B" the more pressure in volume before opening of an aperture are less. It is possible to regulate the size of parameter "B" by means of four sizes: a specific surface density of the safety designs $\left(\rho_{\mathrm{II}}\right)$, depth of seal of the safety designs in $\mathrm{X}_{0}$ aperture, $\Delta \mathrm{P}_{\mathrm{v}}-$ the opening pressure (destruction of communications of the safety designs with the protecting designs), perimeter of apertures through which gases expire. At decrease of the reselt $\left(\rho_{\Pi} * X_{0}\right)$ parameter "B" increases and pressure of opening of an aperture decreases. At increase in pressure of opening $\Delta \mathrm{P}_{\mathrm{v}}$ parameter " $\mathrm{B}$ " increases and the dimensionless pressure of opening also decreases, but absolute pressure increases. Therefore if opening pressure $\Delta \mathrm{P}_{\mathrm{v}}$ decreases, then explosion pressure decreases despite body height of parameter " $\mathrm{B}$ " too. As at discovery of the area for the expiration of gases of at most pressure $\Delta \mathrm{P}_{1 \mathrm{M}}$ it is reached not at the complete opening of an aperture of $\mathrm{X}_{1 \mathrm{M}}$

In work the most typical and possible values of parameter "B" are considered. At these values of the movement safety designs it is possible to break into two periods: driving in an aperture and driving after opening of an aperture. When driving in an aperture of the safety designs accelerates and by the time of escaping of an aperture has the sufficient speed of $X_{1} \approx B_{1} \Delta t_{1}$ shift the providing expiration of gases is defined by this speed.

\section{Conclusion}

In the conclusion it should be noted that before the real work due attention was not paid to a question of seal of the safety designs in apertures. Such situation needs to be reconsidered also at projection of ways of fastening of the safety designs to consider depth of seal of the safety designs in an aperture. At tests of apertures of the safety designs on model installations also often do not consider a possibility of deepening of fastening, believing that the mass of the safety designs and property of clusters of fastening of the safety designs completely resolve an issue of effectiveness of the safety designs. The results received in work unambiguously show that it is necessary to consider depth of seal of the safety designs. Tests of the safety designs on model installations happen at high values of parameter "B" as the speed of explosive combustion at the initial moment of explosion at tests corresponds to laminar flame propagation. Therefore test data often yield excessively optimistic results.

\section{References}

1. Joint venture 12.13013.209. Determination of categories of rooms, buildings and external installations on a fire and explosion and fire hazard. - 05.01.2009. - M.: Ministry of Regional Development of the Russian Federation, (2009).

2. Joint venture 4.13130.2013 Fire protection systems. Restriction of distribution of the fire on subjects to protection. Requirements to space-planning and design decisions. - 
24.06.2013. - M.: Ministry of Regional Development of the Russian Federation, (2013).

3. Joint venture 56.13330.2011. Production buildings. - 20.05.2011. — M.: Ministry of Regional Development of the Russian Federation, (2011).

4. L. P. Pilyugin. Providing. Explosion safety of buildings by means of safety designs. M.: Acc. Pozhnauk, 224p - (2000).

5. V. A. Gorev, E.Yu. Salymova. About a possibility of vibration combustion at internal explosions//Fire and explosion safety. - (2017). - T. 26, No. 5. - Page 41-44.

6. V.A. Gorev. Actions of explosive loads of the protecting designs taking into account vibration combustion // Construction - The Formation of Living Environment / Volume 365, Issue 4, (2018), 042047. DOI: 10.1088/1757-899X/365/4/042047

7. L. Flamm, H. Mache. Combustion of an explosive gas mixture within a closed vessel. Bor. Acad. Wiss. Wien, 126, 9, (1917).

8. H. Gaudry. Set quelques hypotheses admises dans je calcul des vitesses de deflagration a partir des mesutes a la bombe spherique, colloques internal dee C.N.R.S. XVI. Centre National de la Recherche Scientifique Paris. (1998).

9. L.P. Pilyugin. Designs of constructions of explosive productions (theoretical bases of projection). - M.: Stroyizdat, - 316 pages, (1988).

10. L.P. Pilyugin. Prediction of consequences of internal emergency explosions. - M.: - 380 pages (2010).

11. V. A. Gorev, A.I. Plotnikov. Explosion safety at external emergency explosions//the scientific and practical conference "City Structural Complex and Safety of Life Support of Citizens", DIA, Moscow( 2005)

12. O.V. Luzhin, N.N. Popov, B.S. Rastorguyev. Dynamic calculation of constructions on express influences. Section 1. Calculation of designs of constructions on action of blast waves. Stroyizdat, Moscow. 215 pages (1981).

13. E. Yu. Salymova. Dynamics of development of dangerous factors in buildings with the protecting designs from triplex sandwich panels at the fires and explosions: yew. edging. TexH. sciences - M.: MGSU,- 110 pages (2014).

14. V. A. Gorev, E. Yu. Salymova. Use sandwich panels as efficient easily thrown off designs at internal explosions in the production buildings//Fire and explosion safety.T. 19, No. 2. — Page 41-44 - (2010).

15. Yu.H. Polandov, V. A. Babankov. Influence of the location of a source of a ignition indoors on explosion development gas / Fire and explosion safety.- T. 23, No. 3. Page 68- (2015).

16. V.R. Kusnetchov, V.A. Sabelnikov. Turbulentnost and combustion. Publishing house: Science, - 290 pages (1986).

17. V. A. Gorev. Assessment of burning rate of the homogeneous gas mixture at defining influence of instability of a flame//Fire and explosion safety. - (2008). - T. 17, No. 1. Page $12-16$.

18.R.G. Abdel - Gayed and D. Bradly. Dependence of turbulent burning velocity on turbulent Reynolds number and ratio of laminar burning velocity to R.M.S. turbulent velocity. The comb. Institutes. P.1725. (1977).

19. N.A. Kakutkina, A.A. Korzhavin, V.V. Zamashchikov, A.A. Pleslov, V.S. Babkin. Scale modelling of internal gas explosions. Proc. I-st Intern. Seminar on Fire- and Explosion Hazard of Substances and Venting Deflagrations. /Ed. V. Molkov, Moscow: All Russian Research Institute for Fire Protection. - P. 225-230 (1995).

20. D. Bradly. Evolution of flame propagation in large diameter explosions. Fire - and explosions hazard of substances and venting of deflagrations. Proceedings of the second international seminar. Moscow. Russia..pp. 51 - 59. (1998). 